\title{
Aerobic and breathing exercises improve dyspnea, exercise capacity and quality of life in idiopathic pulmonary fibrosis patients: systematic review and meta-analysis
}

\author{
Masatoshi Hanada ${ }^{1,2,3}$, Karina Tamy Kasawara ${ }^{2}$, Sunita Mathur ${ }^{2}$, Dmitry Rozenberg ${ }^{4,5}$, Ryo Kozu ${ }^{1,3}$, \\ S. Ahmed Hassan ${ }^{2,6}$, W. Darlene Reid ${ }^{2,6,7}$ \\ ${ }^{1}$ Cardiorespiratory Division, Department of Rehabilitation Medicine, Nagasaki University Hospital, Nagasaki, Japan; ${ }^{2}$ Department of Physical \\ Therapy, University of Toronto, Toronto, Canada; ${ }^{3}$ Department of Cardiopulmonary Rehabilitation Science, Nagasaki University Graduate School \\ of Biomedical Sciences, Nagasaki, Japan; ${ }^{4}$ Department of Medicine, University of Toronto, Canada; ${ }^{5}$ Respirology, Lung Transplant Program, \\ Toronto General Hospital Research Institute, University Health Network, Canada; ${ }^{6}$ Toronto Rehabilitation Institute, University Health Network, \\ Toronto, Canada; ${ }^{7}$ Interdepartmental Division of Critical Care Medicine, University of Toronto, Toronto, Canada \\ Contributions: (I) Conception and design: M Hanada, KT Kasawara, S Mathur, D Rozenberg, R Kozu, WD Reid; (II) Administrative support: None; \\ (III) Provision of study materials or patients: M Hanada, KT Kasawara, SA Hassan; (IV) Collection and assembly of data: M Hanada, KT Kasawara; \\ (V) Data analysis and interpretation: M Hanada, KT Kasawara, S Mathur, D Rozenberg, SA Hassan, R Kozu, WD Reid; (VI) Manuscript writing: All \\ authors; (VII) Final approval of manuscript: All authors. \\ Correspondence to: Masatoshi Hanada, PT, PhD. Cardiorespiratory Division, Department of Rehabilitation Medicine, Nagasaki University Hospital, \\ 1-7-1 Sakamoto, Nagasaki 852-8501, Japan. Email: mstshnd@nagasaki-u.ac.jp.
}

Background: Idiopathic pulmonary fibrosis (IPF) is a progressive disease associated with significant dyspnea and limited exercise capacity. This systematic review aimed to synthesize evidence of exercise interventions during pulmonary rehabilitation that aim to improve exercise capacity, dyspnea, and healthrelated quality of life (HRQL) in IPF patients.

Methods: Searches were performed in MEDLINE, Embase, CENTRAL, SPORTDiscus, PubMed and PEDro from inception to January 2019 using search terms for: (I) participants: 'IPF or interstitial lung disease'; (II) interventions: 'aerobic training or resistance training or respiratory muscle training'; and (III) outcomes: 'exercise capacity or dyspnea or health-related quality of life'. Two reviewers independently screened titles, abstracts and full texts to identify eligible studies. Methodological quality of studies was assessed using the Downs and Black checklist and meta-analyses were performed.

Results: Of 1,677 articles identified, 14 were included (four randomized controlled trials and 10 prospective pre-post design studies) that examined 362 patients receiving training and 95 control subjects. Exercise capacity was measured with the 6-minute walk distance, peak oxygen consumption, peak work rate, or endurance time for constant work rate cycling, which increased after exercise [aerobic exercise; aerobic and breathing exercises; aerobic and inspiratory muscle training (IMT) exercises] compared to the control groups. Dyspnea scores improved after aerobic and breathing exercises. HRQL also improved after aerobic exercise training alone or combined with breathing exercises. Aerobic training alone or combined with IMT or breathing exercises improved exercise capacity.

Conclusions: Breathing exercises appears to complement exercise training towards improved dyspnea and HRQL in patients with IPF.

Keywords: Dyspnea; interstitial lung diseases; rehabilitation; quality of life; exercise

Submitted May 28, 2019. Accepted for publication Nov 26, 2019.

doi: $10.21037 /$ jtd.2019.12.27

View this article at: http://dx.doi.org/10.21037/jtd.2019.12.27 


\section{Introduction}

Idiopathic pulmonary fibrosis (IPF) is the most common type out of the idiopathic interstitial pneumonias (IIPs) and also associated with the greatest mortality; it is characterized as a chronic disease with progressive parenchymal fibrosis of unknown etiology (1). The incidence of IPF is estimated at 3 to 9 cases per 100,000 per year in North America and Europe (2). IPF has a high mortality rate with a median survival ranging from 2 to 5 years after diagnosis (3). With disease progression, increased dyspnea and skeletal muscle dysfunction contribute to deterioration of exercise capacity, impairment in activities of daily living (ADL) and healthrelated quality of life (HRQL) (4).

The well-established clinical efficacy of pulmonary rehabilitation (PR) in patients with chronic obstructive pulmonary disease (COPD) provides some foundation that it may be beneficial for those with $\operatorname{IPF}(5,6)$. Based on guideline recommendations, both short and longterm benefits can be derived from a PR program $(5,7)$. Similar to COPD, exercise capacity of individuals with IPF is significantly limited due to dyspnea. However, the pathophysiology of IPF may result in differences in PR outcomes. Ventilatory and circulatory impairments in IPF patients generally result in a higher prevalence of exercise-induced hypoxemia, and concomitant pulmonary hypertension compared to those with other chronic lung diseases, which may affect PR tolerance (8).

IPF patients derive gains in exercise capacity, dyspnea reduction, and ADL similar to COPD patients with PR (9). Most exercise programs for IPF patients have included aerobic exercise such as walking and cycling, while others have included a combination of resistance training, inspiratory muscle training (IMT) and breathing exercises (e.g., diaphragmatic breathing (10). To date, beneficial effects from exercise interventions in individuals with IPF have been comprised of various exercise programs, and thus the effectiveness of these training programs requires further verification (11).

Some reviews have provided support for the effectiveness of PR for patients with interstitial lung disease (ILD) $(8,12)$. However, two systematic reviews with meta-analyses only included 5 RCTs; both demonstrated the effectiveness of exercise-centered PR on exercise tolerance [improved 6-minute walk distance (6MWD)] and improved HRQL in patients with IPF $(13,14)$ but specific breathing exercises and IMT were not evaluated. Although, several reports describe the effects of breathing exercise and IMT in
COPD patients (14-16), parallel studies examining these interventions in IPF patients are scarce (17). Certainly, such interventions warrant synthesis in a systematic review because of their potential benefit to improve symptoms and daily function.

The purpose of this systematic review was to synthesize evidence from studies that evaluated the efficacy of different types of exercises, including breathing exercises and IMT, in patients with IPF. We evaluated the impact of aerobic exercise training alone and when paired with resistance training, breathing exercises or IMT and their effects on exercise capacity, dyspnea, and HRQL.

\section{Methods}

\section{Search strategy}

A search strategy was developed with the assistance of a reference librarian. Searches were performed from inception to January $22^{\text {nd }}$, 2019 in six databases including MEDLINE (including Epub Ahead of Print, In-Process \& Other Non-Indexed Citations, Daily), Embase, Cochrane Central Register of Controlled Trials (CENTRAL), SPORTDiscus and PubMed and Physiotherapy Evidence Database. Reference lists of the included papers were manually reviewed. Only studies published in English and Japanese were included. The review was registered with the PROSPERO database: CRD42018091411 and this study was reported in accordance with the PRISMA standards guidelines (18).

Scientific databases were searched using the Medical Subject Headings and keywords related to: (I) participants: 'ILD, IIPs or IPF or pulmonary fibrosis or interstitial fibrosis or nonspecific interstitial pneumonia or lung fibrosis'; (II) interventions: 'aerobic training or resistance training or respiratory muscle training'; and (III) outcomes: 'exercise capacity or dyspnea or ADL or HRQL' (Supplement A).

\section{Study criteria}

Studies were included if: (I) the cohort included patients with IIPs; (II) an exercise program was the primary intervention that included a single intervention or a combination of aerobic, resistance, IMT or breathing exercise training (diaphragmatic or pursed lip); (III) they had any of the following outcomes-exercise capacity measured with $6 \mathrm{MWD}$ (19), maximal rate of oxygen consumption 
(peak $\mathrm{VO}_{2}$ ), peak work rate (peak WR), endurance time $\left(t_{\text {lim }}\right)$ from a constant work rate cycle ergometry test, dyspnea score (at rest and post exercise) measured with the modified Borg scale (20), Medical Research Council score (21), modified Medical Research Council (mMRC) score (22), Baseline Dyspnea Index (BDI) (23), visual analog scale that assessed dyspnea (VAS) (24); HRQL evaluated using St. George's Respiratory Questionnaire (SGRQ) (25), the SGRQ-I (IPF version) (26) or 36-Item Short-Form Health Survey (SF-36) (27); and (IV) the study design was either a randomized control trial (RCT) or prospective observational study with pre-post design.

Studies were excluded if they: (I) involved participants other than IIPs, connective tissue disorders and extraparenchymal causes of restriction; or (II) were crosssectional, retrospective, systematic reviews, editorial letters or conference abstracts without full-text.

\section{Study selection and data extraction}

Two investigators (M.H and K.T.K) independently screened abstracts to be selected for full text review. The same two investigators performed full-text review independently to determine inclusion for data synthesis and meta-analyses. Data was independently extracted and confirmed by the two reviewers. Any disagreements regarding the selected articles were discussed between reviewers until consensus was achieved. A third person was not required to achieve agreement.

\section{Methodological appraisal}

The methodological quality of each study was assessed independently by two investigators using the Downs and Black checklist (28) and scores were discussed until consensus was reached. Each study was assessed on items in the following categories: (I) reporting; (II) external validity; (III) internal validity (bias); (IV) internal validity (confounding); and (V) power. The quality of studies meeting $>75 \%$ of the applicable criteria was considered high, $60-74 \%$ moderate, and $<60 \%$ deemed low (29).

\section{Statistical analysis}

The Cochrane systematic review software Review Manager (version 5.3.5) was used to determine the mean differences, which is calculated as the absolute difference between the mean values of the exercise versus control groups; or between the pre versus post exercise effects. In addition, the $95 \%$ confidence intervals were also calculated by this software. Meta-analyses were conducted to evaluate the effects of exercise training interventions on exercise capacity, dyspnea, and HRQL. The change in 6MWD, peak $\mathrm{VO}_{2}$, peak $W R$, and $t_{\text {lim }}$ from a constant WR cycle ergometry test were analyzed as continuous outcomes and expressed as between-groups differences in means and $95 \%$ confidence intervals. Forest plots were constructed to display the effects of exercise in individual studies and evaluate statistical heterogeneity, where $\mathrm{I}^{2}$ values of $<25 \%$, $26-74 \%$ and $>75 \%$ represented small, moderate and large levels of heterogeneity, respectively (30). Fixed-effects models were used for analyses.

\section{Results}

\section{Study selection}

Fourteen full-text articles of the 1,677 reviewed abstracts were included in this review (Figure 1). In these reports, data from 362 IPF trained patients and 95 control subjects were reported. The authors of 4 papers were contacted for more information and 3 provided the required data for meta-analyses (31-34). Of this number, 4 RCTs included 71 patients in the treatment groups and 71 patients in the control groups (31,35-37). Ten prospective observational studies had a pre-post design that included 291 patients that received exercise training (9,32-34,38-42) and one of these reports had 24 patients assigned in a non-random fashion to a control group (43). The rehabilitation programs included aerobic training, resistance training, breathing exercises and IMT that were provided in 2-3 sessions per week for 8 to 12 weeks (Table 1).

\section{Study quality}

The mean quality assessment score of the included studies was $16 \pm 2$ out of 28 , which equated to $56 \% \pm 7 \%$ (range: 46-71\%) (Table 2). Four RCTs and one pre-post study had moderate quality scores, while the other nine pre-post design studies had low quality scores. All studies received points in the external validity category for reporting a hypothesis, a clear description of methods and participant characteristics, use of appropriate statistics, and reliable and accurate outcome measures. The less commonly reported items were an a priori power calculation and whether the subject sample was representative of the general IPF population (Table 2). 


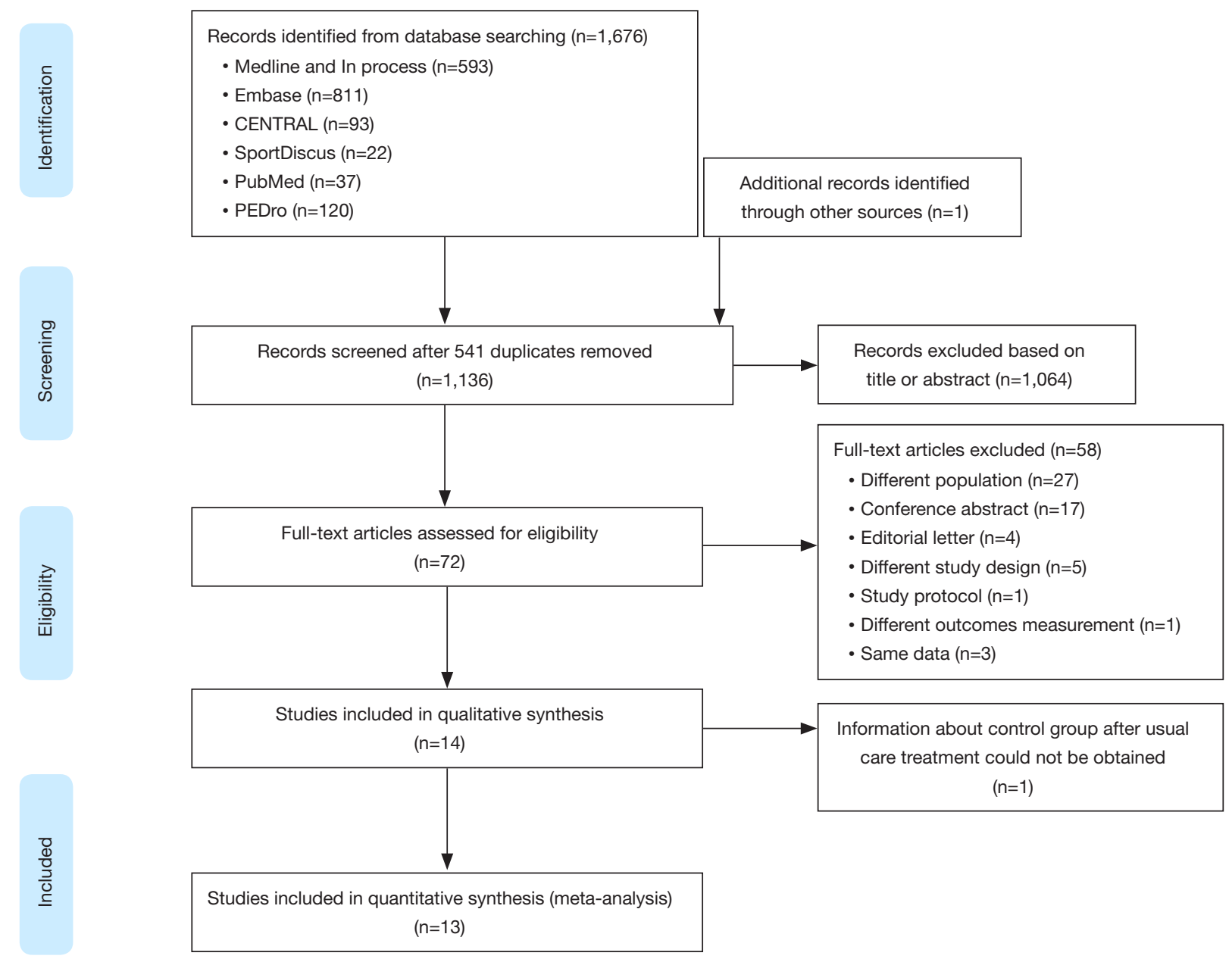

Figure 1 Flow chart of retrieval, screening and inclusion of articles in systematic review.

\section{Exercise capacity}

The $6 \mathrm{MWD}$, peak $\mathrm{VO}_{2}$, peak WR, and $\mathrm{t}_{\text {lim }}$ on a constant WR cycle ergometer tests were used to evaluate exercise capacity in eleven, two, three and five studies, respectively. The mean difference of the $6 \mathrm{MWD}$ was significant and in favour of patients engaged in aerobic exercise training, aerobic training with breathing exercise, or aerobic exercise training with IMT compared to controls $(\mathrm{P}<0.00001)$ with no subgroup differences $(\mathrm{P}=0.15)$ (Figure $2 A)$. Eight studies that examined $6 \mathrm{MWD}$ pre- and post-exercise found overall significant improvement in favour of individuals with exercise training $(\mathrm{P}<0.00001)$, but no significant subgroup differences $(\mathrm{P}=0.79)$ (Figure 2B).

Significant increases in peak WR were shown in RCTs that applied combinations of aerobic training with breathing exercises or IMT $(\mathrm{P}<0.00001)$ with greater improvement in the subgroup that applied breathing exercises $(\mathrm{P}=0.0003)$ (Figure 3A). However, no significant improvements in peak WR were shown in favour of aerobic exercise training and IMT in one pre-post design study $(\mathrm{P}=0.29)$ (Figure 3B). Peak $\mathrm{VO}_{2}$ was greater in the exercise training compared to the control group in one study (37), while no significant pre- and post-effect was found in a study measuring the effect of aerobic training with IMT over 10 weeks.

The mean difference of constant work rate cycling $t_{\text {lim }}$ was significant and in favour of individuals in the aerobic exercise training, or aerobic exercise training with IMT groups compared to controls $(\mathrm{P}<0.00001)$ with greater improvement in the latter $(\mathrm{P}<0.00001)$ (Figure $3 C$ ). Furthermore, significant differences in favour of aerobic exercise training, or aerobic exercise training and IMT were demonstrated in studies with pre- and post-design $(\mathrm{P}<0.0001)$ (Figure 3D). 


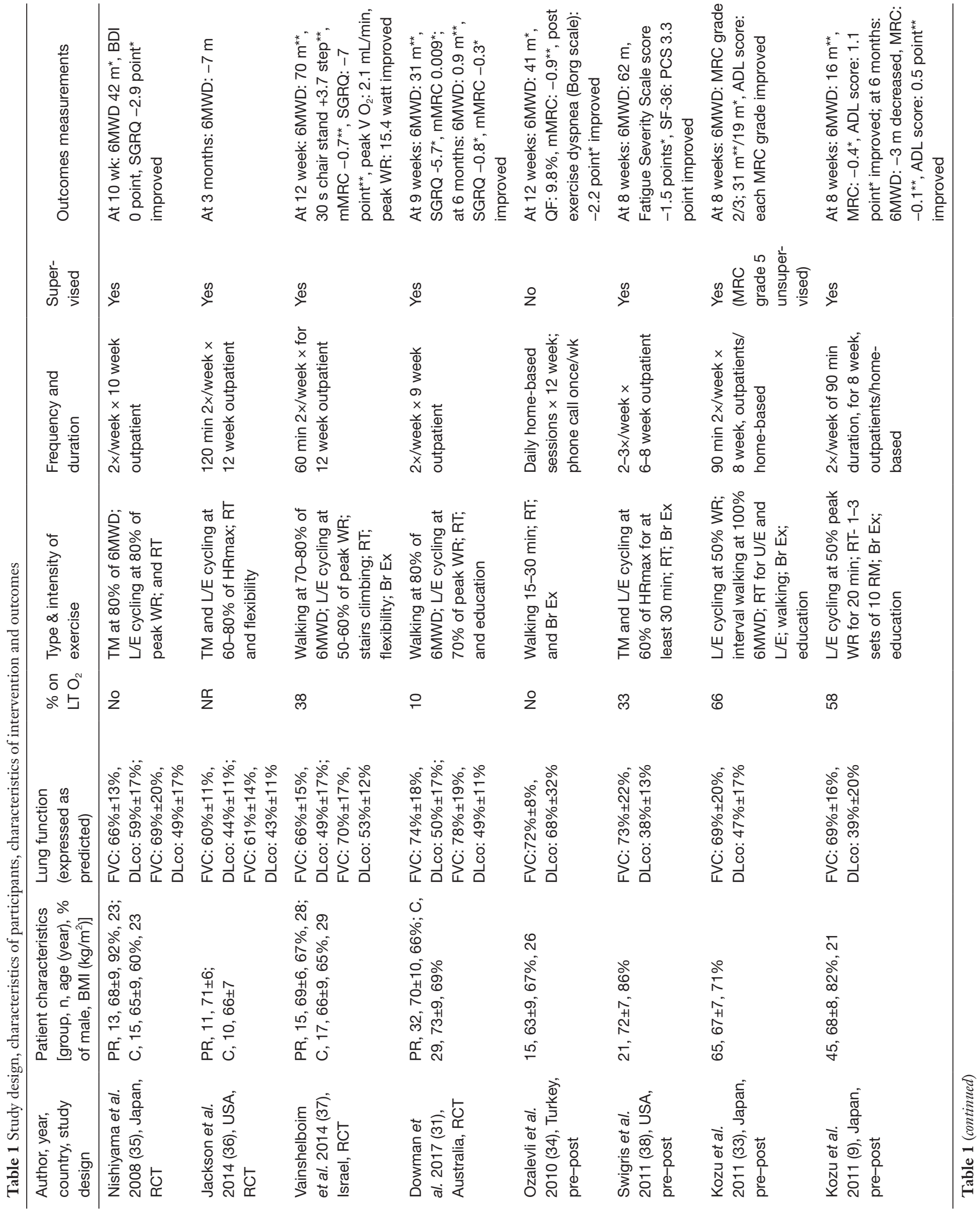




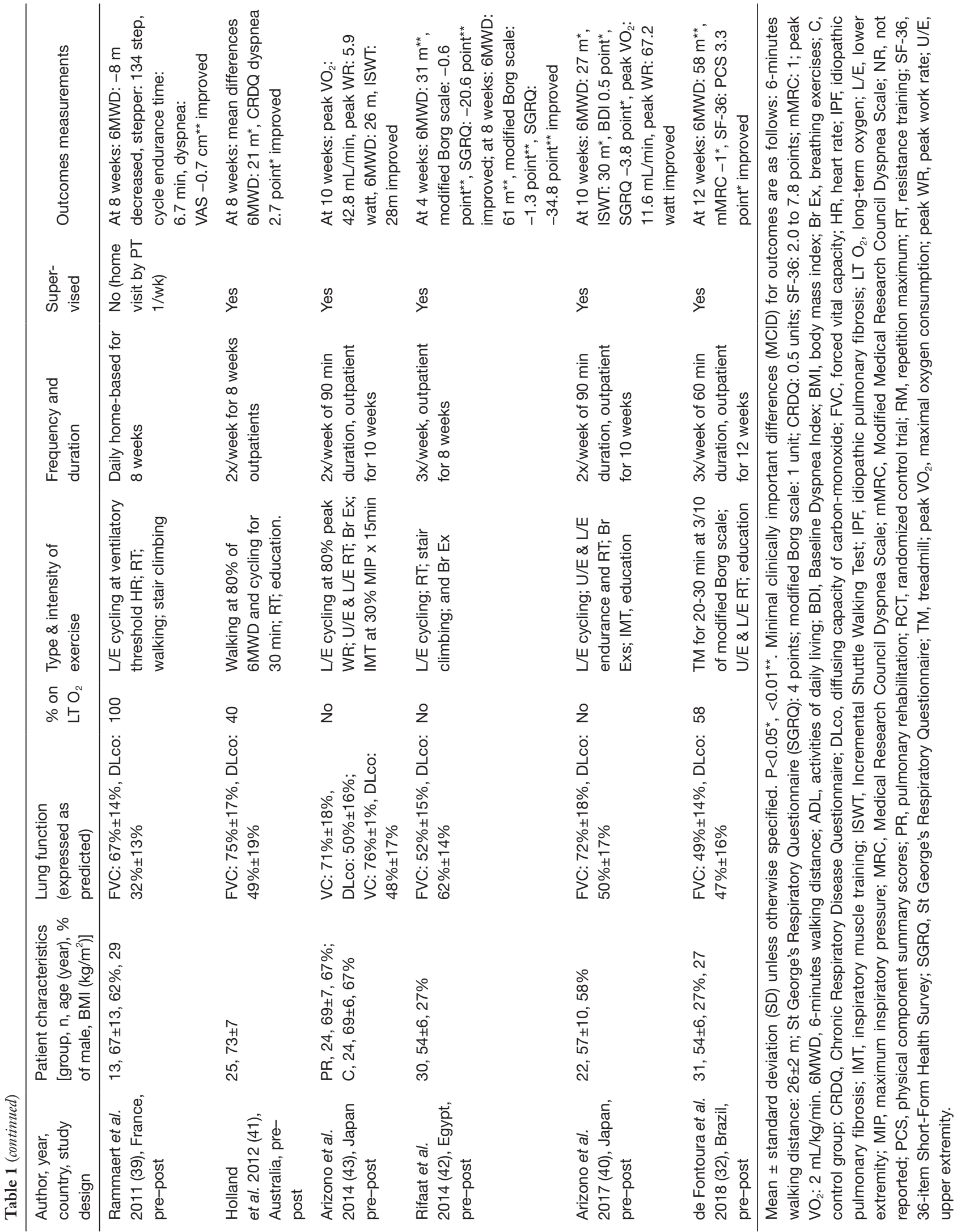


Table 2 Quality assessment scores based on the modified Downs and Black Checklist

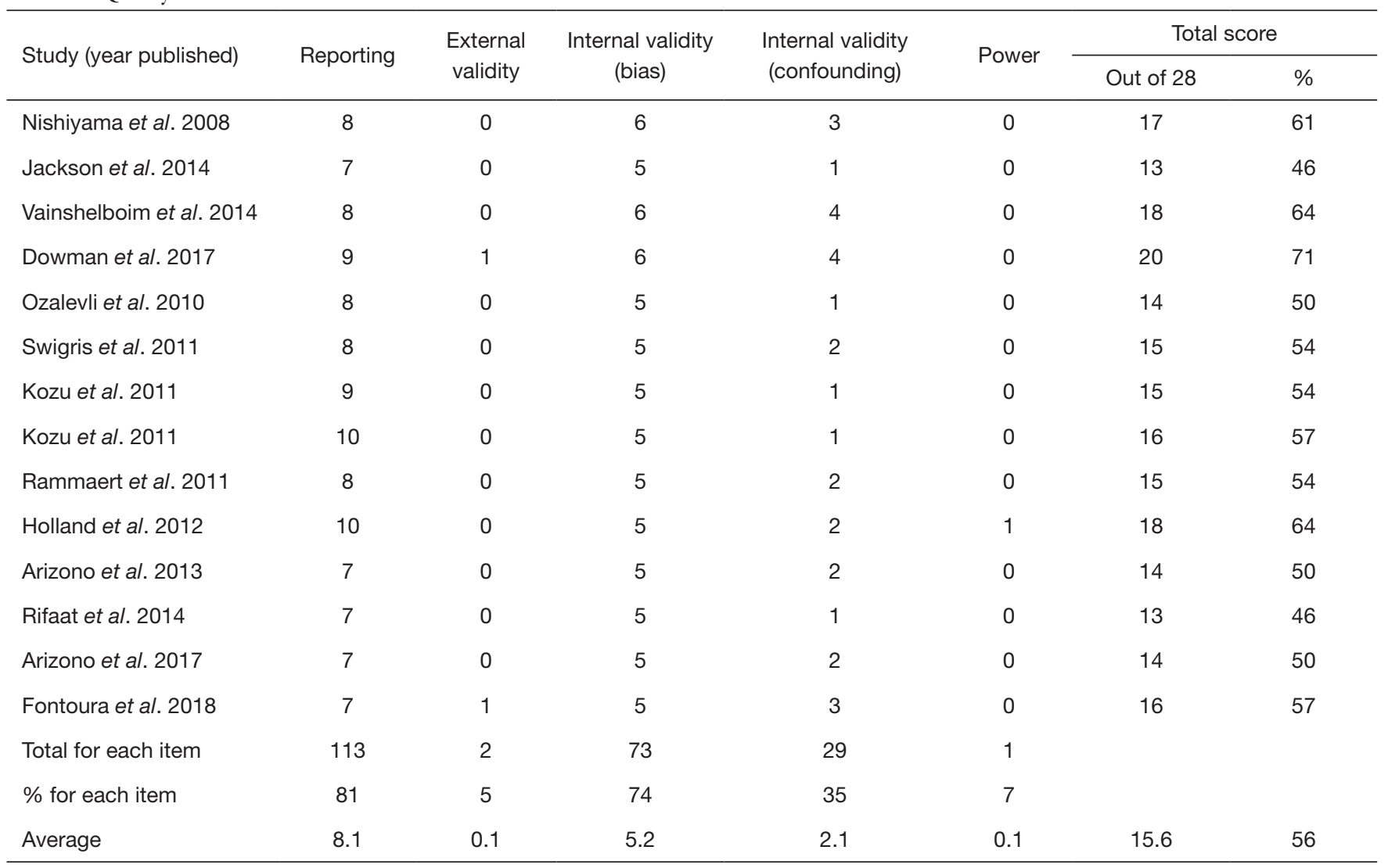

All questions were scored on the following scale: yes -1 , unable to determine -0, no- 0 .

\section{Dyspnea}

Dyspnea was evaluated in twelve studies, while data from seven were pooled for meta-analyses. Five studies were excluded because data was not similar enough to be combined in the meta-analysis. Five studies used the modified Medical Research Council scale (9,32-34,37), while the others used the BDI (35), Chronic Respiratory Disease Questionnaire (CRDQ) (41) and VAS (39). The RCTs showed a significant reduction in dyspnea for the overall effect $(\mathrm{P}=0.01)$ and subgroup analyses demonstrated a greater improvement when exercise training was combined with breathing exercise versus control groups $(\mathrm{P}=0.0002)$ (Figure $4 A$ ). A significant decrease in dyspnea was found between pre- and post-intervention studies $(\mathrm{P}=0.0008)$ but no subgroup differences were shown $(\mathrm{P}=0.69)$ (Figure 4B).

\section{$H R Q L$}

The HRQL was evaluated in nine studies: four studies used
SGRQ $(35,37,42,43)$, (Figure 5) and five studies used SF36 (Figure 6) $(9,32-34,38)$. Compared to the control groups, the mean difference in SGRQ showed a significant overall effect in favour of the aerobic exercise training, and the aerobic exercise training with breathing exercise groups $(\mathrm{P}<0.00001)$ with only a tendency of greater improvement in the latter $(\mathrm{P}=0.06)$ (Figure $5 A)$. In a parallel fashion, SGRQ score showed a significant improvement posttraining in the aerobic exercise training with breathing exercise group $(\mathrm{P}=0.006)$ (Figure $5 B)$. In five studies that evaluated HRQL using the SF-36 (10,28-30,40), the mean difference in all domains significantly increased after the exercise training regimens (Figure 6).

\section{Discussion}

This systematic review with meta-analyses demonstrated that PR utilizing aerobic training alone or combined with breathing exercises or IMT led to significant improvements in exercise capacity, dyspnea and HRQL. Improvement in 


\section{A Exercise versus Control Group}

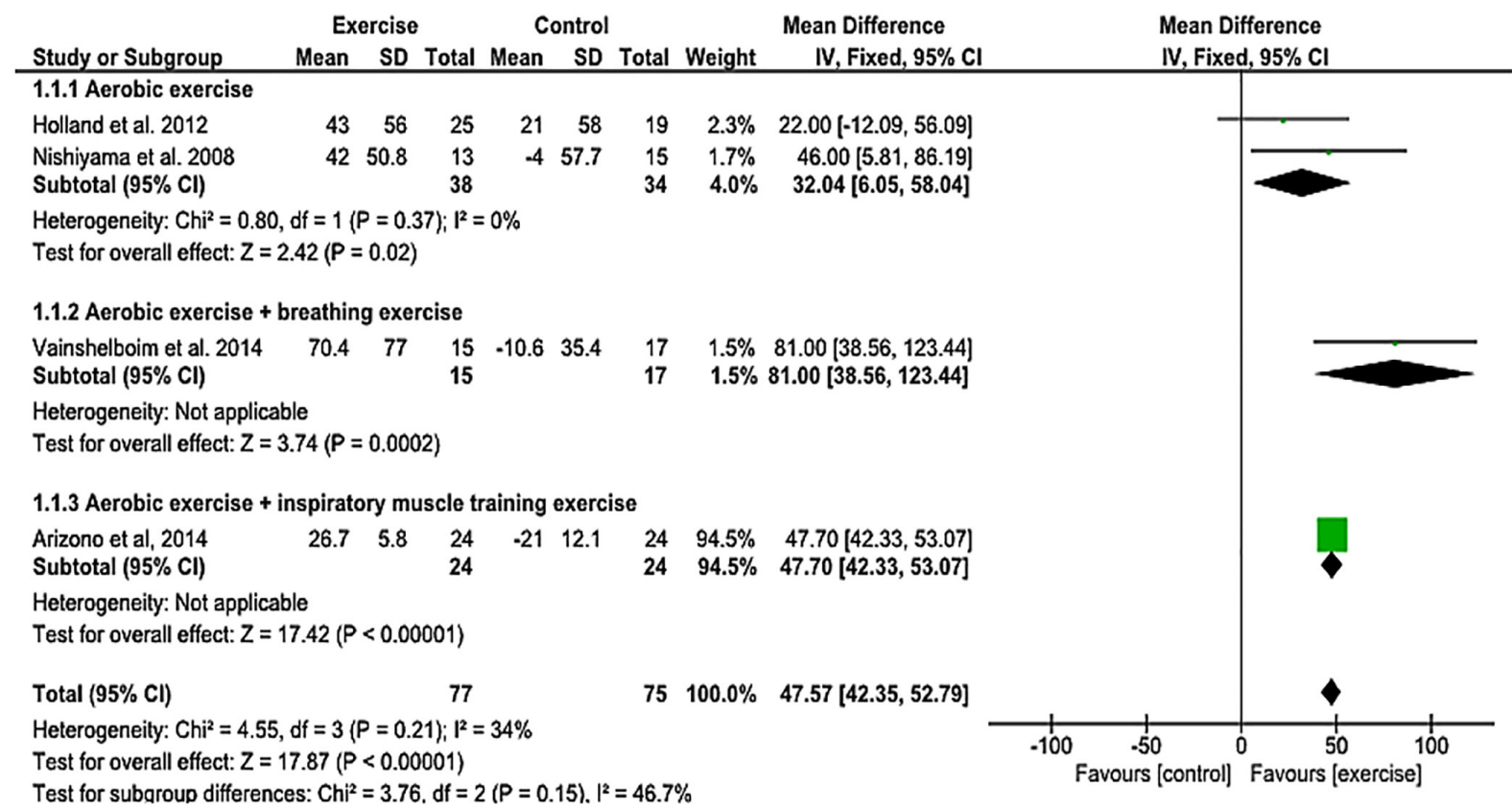

\section{B Pre versus post exercise training}

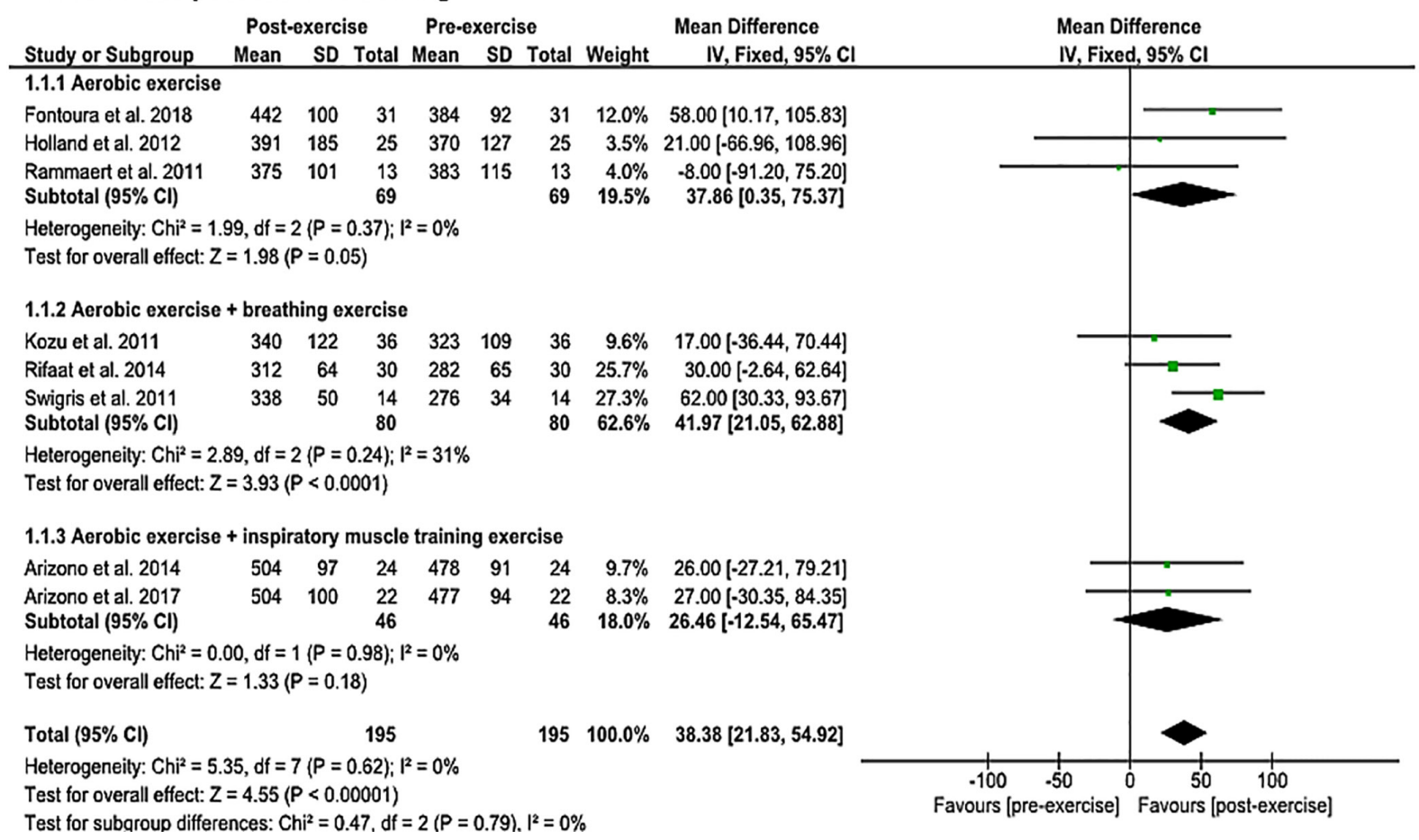

Figure 2 Change in 6-minute walk distance (m). (A) Exercise versus control; (B) pre and post exercise. Symbols: for single studies, the squares indicate the mean difference and the relative size of the square is an indication of the weighting of this study towards the overall effect. The endpoints of the horizontal lines are the upper and lower $95 \%$ confidence interval. The large diamonds represent the summed data for the subgroups and all studies included in the meta-analysis; the midpoint of the diamond indicates the mean difference whereas the endpoints are the upper and lower 95\% confidence interval. 95\% CI, 95-percent confidence interval; IV, inverse variance; SD, standard deviation. 
A Peak Work Rate (watts) - Exercise versus Control Group

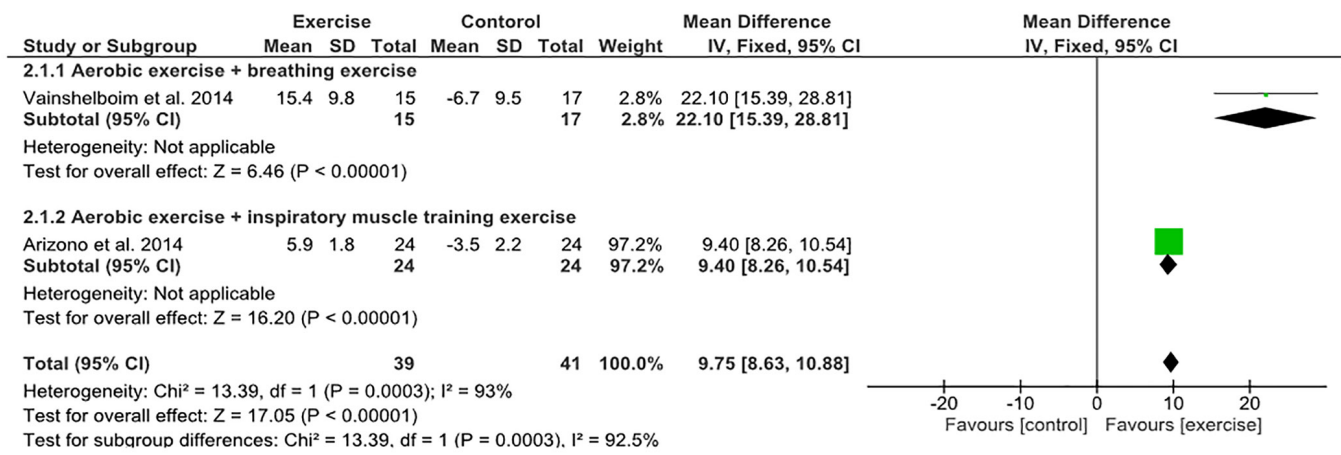

B Peak Work Rate (watts) - Pre versus post exercise training

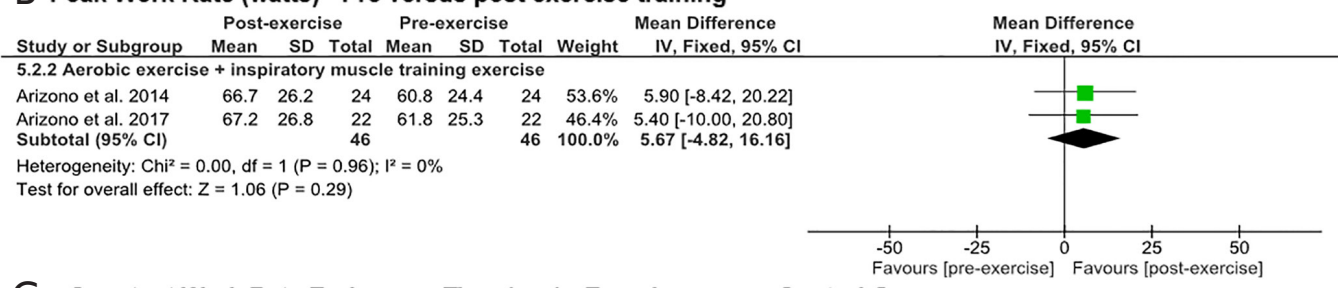

C Constant Work Rate Endurance Time (sec) - Exercise versus Control Group

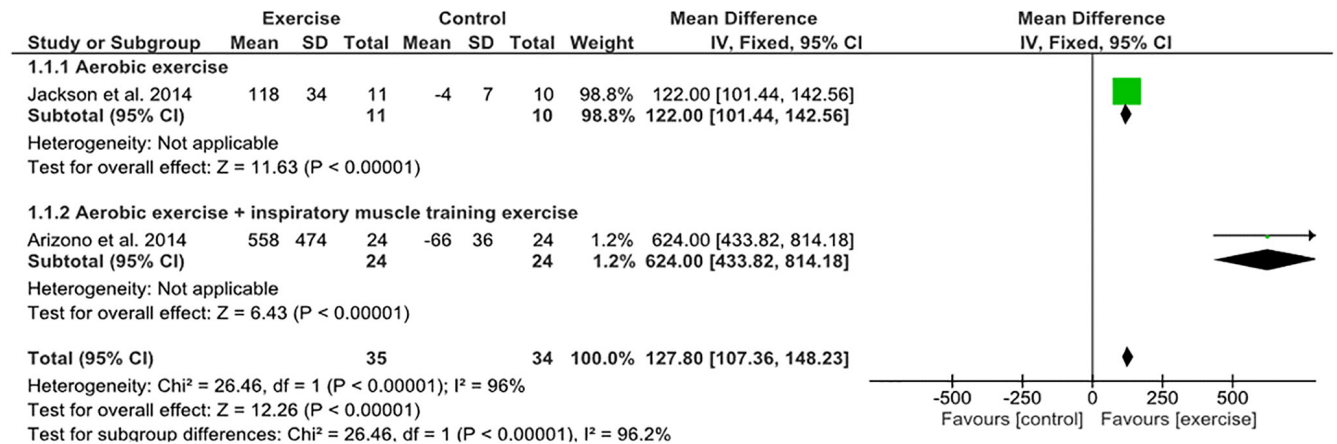

D Constant Work Rate Endurance Time(sec) - Pre versus post exercise training

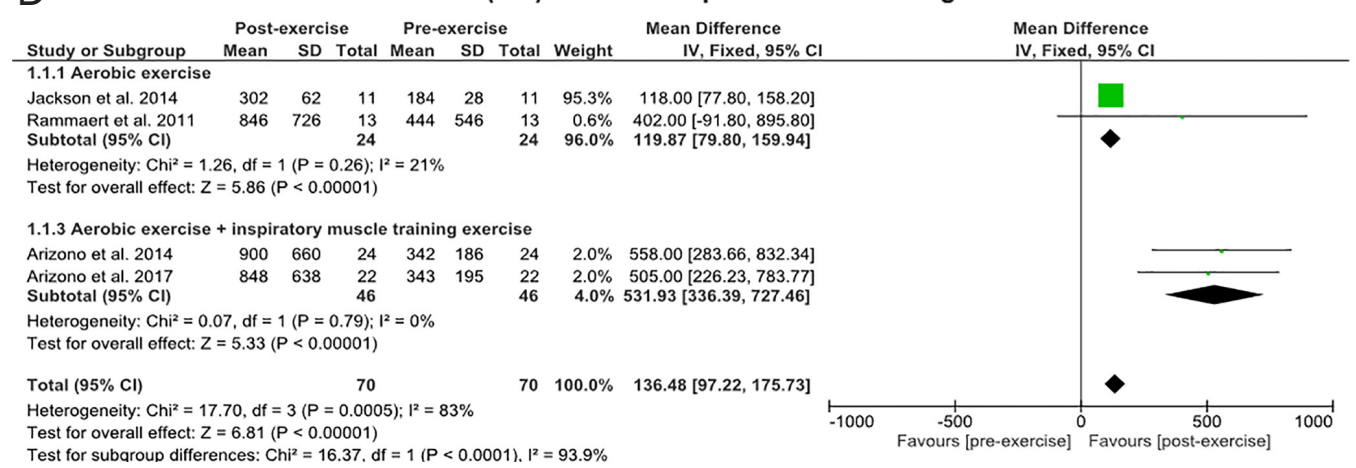

Figure 3 Change in cycle ergometry outcome. (A) Peak work rate (watt)—exercise versus control; (B) peak work rate (watt)—pre and post exercise; (C) constant work rate endurance time (s) - exercise versus control; (D) Constant work rate endurance time (s) - pre and post exercise. Symbols: for single studies, the squares indicate the mean difference and the relative size of the square is an indication of the weighting of this study towards the overall effect. The endpoints of the horizontal lines are the upper and lower $95 \%$ confidence interval. The large diamonds represent the summed data for the subgroups and all studies included in the meta-analysis; the midpoint of the diamond indicates the mean difference whereas the endpoints are the upper and lower 95\% confidence interval. 95\% CI, 95-percent confidence interval; IV, inverse variance; SD, standard deviation. 


\section{A Exercise versus Control Group}

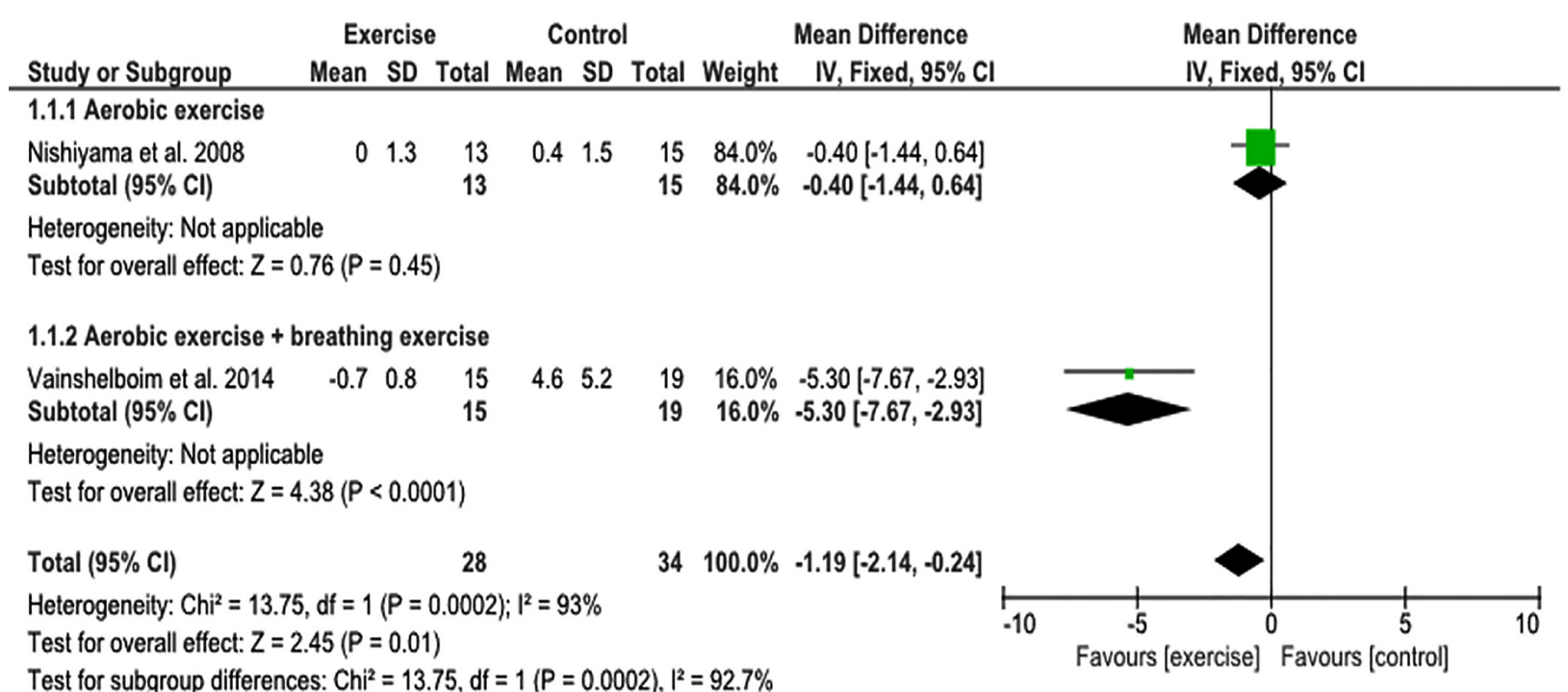

\section{B Pre versus post exercise training - $\%$ change}

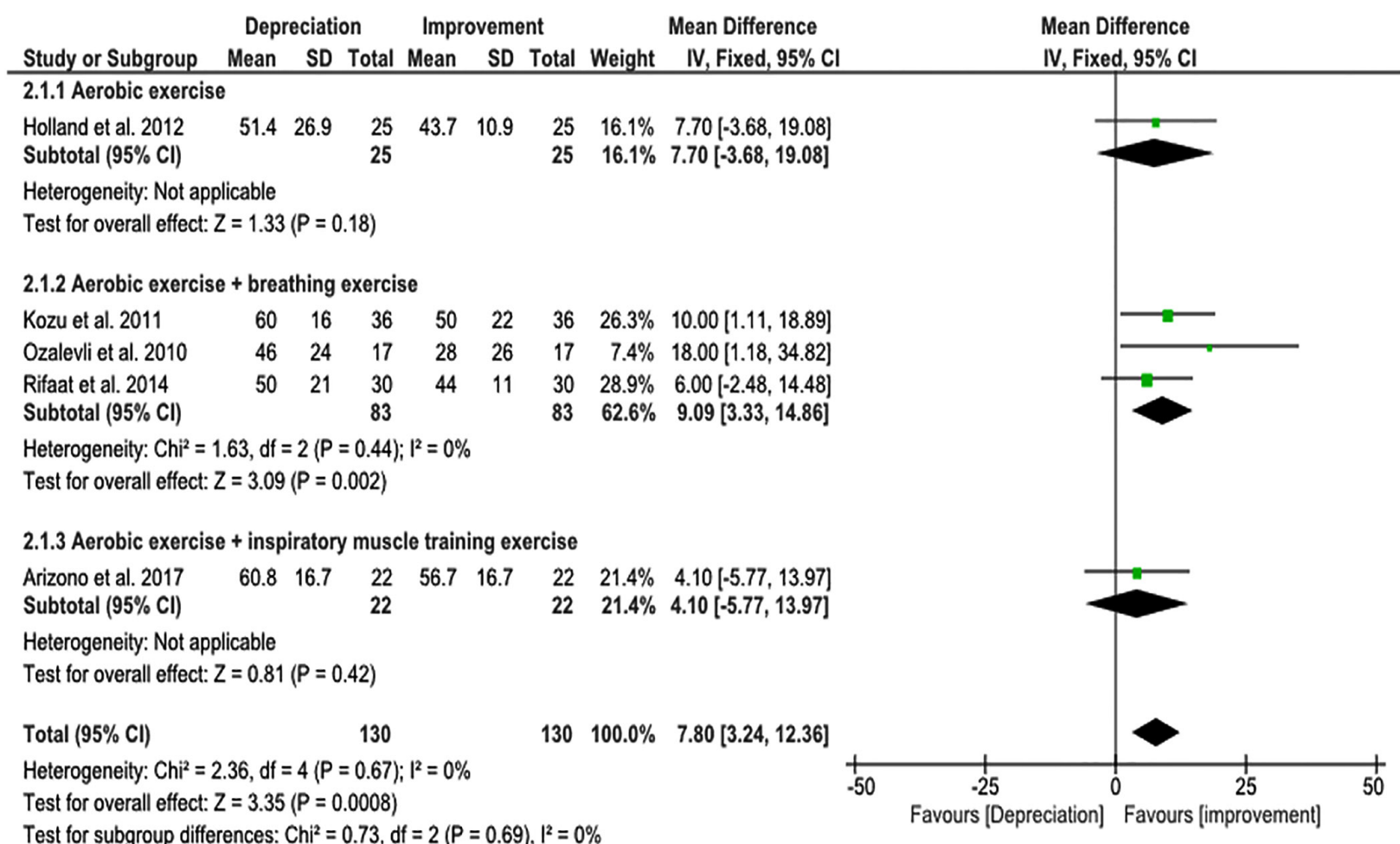

Figure 4 Change in dyspnea score. (A) Exercise versus control; (B) \% improvement of pre and post exercise. Symbols: for single studies, the squares indicate the mean difference and the relative size of the square is an indication of the weighting of this study towards the overall effect. The endpoints of the horizontal lines are the upper and lower 95\% confidence interval. The large diamonds represent the summed data for the subgroups and all studies included in the meta-analysis; the midpoint of the diamond indicates the mean difference whereas the endpoints are the upper and lower 95\% confidence interval. 95\% CI, 95-percent confidence interval; IV, inverse variance; SD, standard deviation. 
A

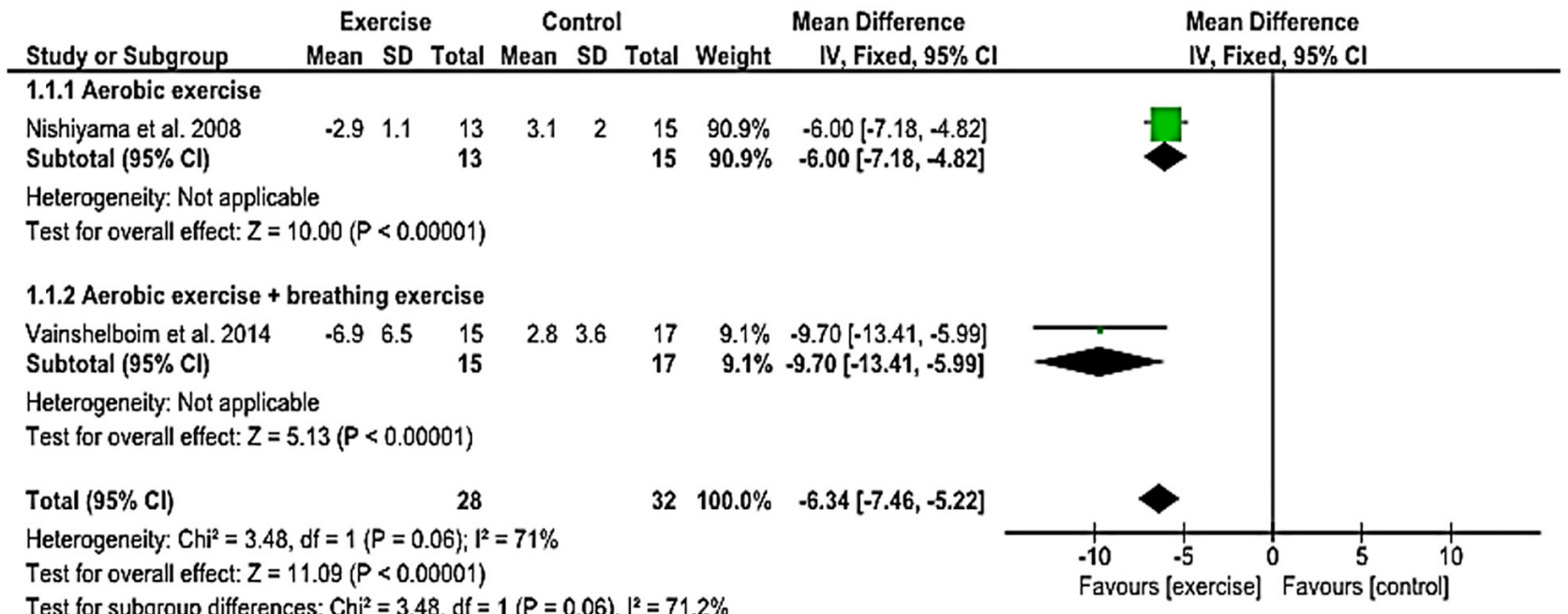

B

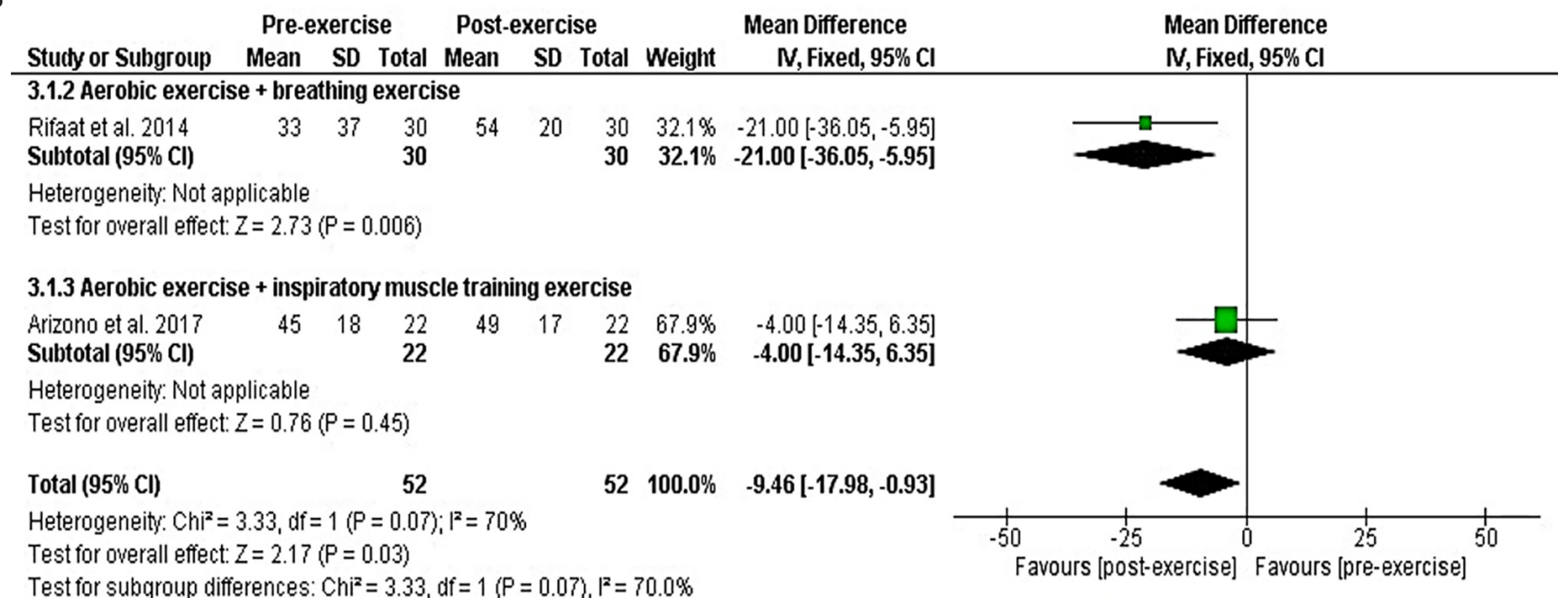

Figure 5 Change in St. George's Respiratory Questionnaire (point). (A) Exercise versus control; (B) Pre and post exercise. Symbols: for single studies, the squares indicate the mean difference and the relative size of the square is an indication of the weighting of this study towards the overall effect. The endpoints of the horizontal lines are the upper and lower 95\% confidence interval. The large diamonds represent the summed data for the subgroups and all studies included in the meta-analysis; the midpoint of the diamond indicates the mean difference whereas the endpoints are the upper and lower 95\% confidence interval. 95\% CI, 95-percent confidence interval; IV, inverse variance; SD, standard deviation.

exercise capacity was shown in the $6 M W D$, peak WR and most consistently in the $t_{\text {lim }}$ of constant WR cycle ergometry. Aerobic training combined with breathing exercises not only improved exercise capacity but appeared to have a complementary effect on improving dyspnea scores. To the best of our knowledge, this is the first systematic review to examine PR interventions that included breathing exercises or IMT combined with exercise training.
In this meta-analysis, exercise training showed a significant improvement in the $6 \mathrm{MWD}$. Aerobic training combined with breathing exercises appeared to show a complementary effect. Our meta-analysis of RCTs showed an overall significant mean difference of $48 \mathrm{~m}$ in the 6MWD and the one RCT that utilized breathing exercises showed a mean difference of $81 \mathrm{~m}$. An increase of 24 to $45 \mathrm{~m}$ in $6 \mathrm{MWD}$ has been reported as the minimal clinically 


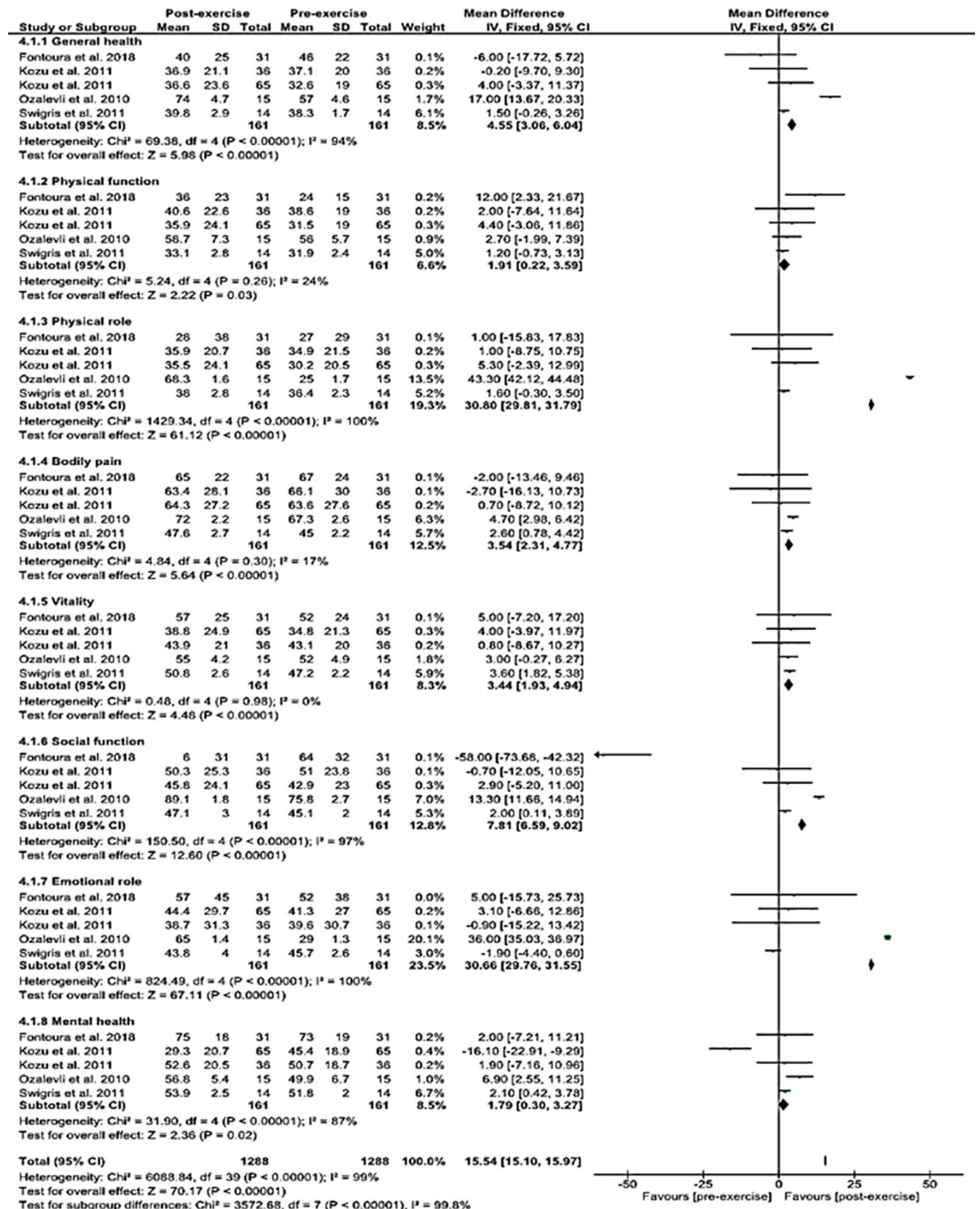

Figure 6 The 36-item Short-Form Health Survey (SF-36) pre versus post-exercise. Symbols: for single studies, the squares indicate the mean difference and the relative size of the square is an indication of the weighting of this study towards the overall effect. The endpoints of the horizontal lines are the upper and lower $95 \%$ confidence interval. The large diamonds represent the summed data for the subgroups and all studies included in the meta-analysis; the midpoint of the diamond indicates the mean difference whereas the endpoints are the upper and lower 95\% confidence interval. 95\% CI, 95-percent confidence interval; IV, inverse variance; SD, standard deviation. 
important difference in patients with IPF (44). These data suggest that breathing exercise with aerobic training may provide added benefit for patients with IPF. These findings are consistent with previously reported improvements in exercise tolerance with PR in individuals with $\operatorname{ILD}(8,12,13)$.

Aerobic exercise combined with IMT was more beneficial in improving constant $W \mathrm{R} \mathrm{t}_{\text {lim }}$ compared to aerobic exercise training alone. Nykvist et al. performed IMT with aerobic exercise in patients with IPF for 8 weeks and reported a significant increase in exercise capacity and decrease in dyspnea symptoms compared to the control group (45). Aerobic exercise plus IMT may be beneficial because increased inspiratory muscle strength can improve the efficiency of the respiratory muscles required for ventilation (46). Furthermore, improved exercise endurance may result in improved aerobic capacity, and hence reduced ventilatory load during exercise.

The meta-analysis of RCTs indicated that dyspnea scores improved to a greater extent when breathing exercises were combined with aerobic exercise training $(33,34,42)$ than aerobic exercise training alone (37) or when combined with IMT $(40,41)$. Vainshelboim et al. (37) proposed several potential benefits from the repetitive stimuli of high ventilatory demands during exercise sessions, chest expansion during deep breathing exercises and stretching of the thoracic muscles. They postulated that these stimuli may contribute to a more efficient breathing pattern, improved strength of respiratory muscles, enhanced pleural elasticity and pulmonary compliance within the lung tissue, and decreased dyspnea perception following the exercise training program $(4,10,37)$. These mechanisms that are possibly induced by aerobic and breathing exercises require further investigation.

Aerobic training plus breathing exercises showed greater benefits compared to aerobic exercise training alone or aerobic exercise training plus IMT in improving HRQL scores. These findings are consistent with other studies that used the SGRQ in ILD patients $(47,48)$. Using the disease specific SGRQ, the two RCTs in this review showed a combined mean difference of 6.3 favoring improvement $(35,37)$, which exceeded the minimal clinically important difference of 4 (49). Our results reinforce that aerobic training combined with breathing exercises is a critical component of $\mathrm{PR}$ for improving functional capacity and HRQL in ILD.

The mean quality assessment score of 16 out of 28 was low, likely due to inclusion of prospective studies with pre- and post-intervention designs. Furthermore, internal validity might have been compromised due to selection bias of subjects included in the PR exercise program as they may have been relatively more stable. Moreover, many studies did not comment on the power, external or internal validity, which may limit the generalizability of the results.

This systematic review with meta-analysis has some limitations. Firstly, the independent impact of each exercise intervention could not be ascertained as several studies provided combinations of exercise training modalities in either a supervised or home-based setting. Secondly, disease severity, variability and progression may have influenced the impact of PR, but the majority of studies were in patients with mild-moderate disease and about one-third of patients were using supplemental oxygen.

In summary, this review showed significant improvements in exercise capacity, dyspnea and HRQL with the greater benefits derived from the combination of breathing and aerobic exercises for dyspnea and HRQL. Future studies should focus on examining the benefits and mechanisms of improvement from individual exercises, so interventions providing optimal results may be combined to maximize benefits for IPF patients.

\section{Acknowledgments}

We would like to acknowledge Jessica Babineau (librarian) for her support in conducting the literature search. Dmitry Rozenberg is supported by the Sandra Faire and Ivan Fecan Professorship in Rehabilitation Medicine.

Funding: None.

\section{Footnote}

Conflicts of Interest: The authors have no conflicts of interest to declare.

Ethical Statement: The authors are accountable for all aspects of the work in ensuring that questions related to the accuracy or integrity of any part of the work are appropriately investigated and resolved.

Open Access Statement: This is an Open Access article distributed in accordance with the Creative Commons Attribution-NonCommercial-NoDerivs 4.0 International License (CC BY-NC-ND 4.0), which permits the noncommercial replication and distribution of the article with the strict proviso that no changes or edits are made and the original work is properly cited (including links to both the 
formal publication through the relevant DOI and the license). See: https://creativecommons.org/licenses/by-nc-nd/4.0/.

\section{References}

1. Oldham JM, Noth I. Idiopathic pulmonary fibrosis: early detection and referral. Respir Med 2014;108:819-29.

2. Hutchinson J, Fogarty A, Hubbard R, et al. Global incidence and mortality of idiopathic pulmonary fibrosis: a systematic review. Eur Respir J 2015;46:795-806.

3. Raghu G, Collard HR, Egan JJ, et al. An official ATS/ ERS/JRS/ALAT statement: idiopathic pulmonary fibrosis: evidence-based guidelines for diagnosis and management. Am J Respir Crit Care Med 2011;183:788-824.

4. Kenn K, Gloeckl R, Behr J. Pulmonary rehabilitation in patients with idiopathic pulmonary fibrosis--a review. Respiration 2013;86:89-99.

5. Spruit MA, Singh SJ, Garvey C, et al. An official American Thoracic Society/European Respiratory Society statement: key concepts and advances in pulmonary rehabilitation. Am J Respir Crit Care Med 2013;188:e13-64.

6. Swigris JJ, Stewart AL, Gould MK, et al. Patients' perspectives on how idiopathic pulmonary fibrosis affects the quality of their lives. Health Qual Life Outcomes. 2005;3:61.

7. Perez-Bogerd S, Wuyts W, Barbier V, et al. Short and long-term effects of pulmonary rehabilitation in interstitial lung diseases: a randomised controlled trial. Respir Res 2018;19:182.

8. Dowman L, Hill CJ, Holland AE. Pulmonary rehabilitation for interstitial lung disease. Cochrane Database Syst Rev 2014;(10):CD006322.

9. Kozu R, Senjyu H, Jenkins SC, et al. Differences in response to pulmonary rehabilitation in idiopathic pulmonary fibrosis and chronic obstructive pulmonary disease. Respiration 2011;81:196-205.

10. Vainshelboim B. Exercise training in idiopathic pulmonary fibrosis: is it of benefit? Breathe (Sheff) 2016;12:130-8.

11. Puglisi S, Torrisi SE, Vindigni V, et al. New perspectives on management of idiopathic pulmonary fibrosis. Ther Adv Chronic Dis. 2016;7:108-20.

12. Holland A, Hill C. Physical training for interstitial lung disease. Cochrane Database Syst Rev 2008;(4):CD006322.

13. Gomes-Neto M, Silva CM, Ezequiel D, et al. Impact of pulmonary rehabilitation on exercise tolerance and quality of life in patients with idiopathic pulmonary fibrosis: A systematic review and meta-analysis. J Cardiopulm Rehabil Prev 2018;38:273-8.
14. Holland AE, Hill CJ, Jones AY, et al. Breathing exercises for chronic obstructive pulmonary disease. Cochrane Database Syst Rev 2012;10:CD008250.

15. Beaumont $M$, Forget $P$, Couturaud F, et al. Effects of inspiratory muscle training in COPD patients: A systematic review and meta-analysis. Clin Respir J 2018;12:2178-88.

16. Reid WD, Loveridge BM. Physiotherapy management of patients with chronic obstructive airways disease. Physiother Can 1983;35:183-95.

17. Parisien-La Salle S, Abel Rivest E, Boucher VG, et al. Effects of Pursed Lip Breathing on Exercise Capacity and Dyspnea in Patients With Interstitial Lung Disease: A randomized, crossover study. J Cardiopulm Rehabil Prev 2019;39:112-7.

18. Moher D, Liberati A, Tetzlaff J,et al. Preferred reporting items for systematic reviews and meta-analyses: the PRISMA Statement. Open Med 2009;3:e123-30.

19. ATS Committee on Proficiency Standards for Clinical Pulmonary Function Laboratories. ATS statement: guidelines for the six-minute walk test. Am J Respir Crit Care Med 2002;166:111-7.

20. Muza SR, Silverman MT, Gilmore GC, et al. Comparison of scales used to quantitate the sense of effort to breathe in patients with chronic obstructive pulmonary disease. Am Rev Respir Dis 1990;141:909-13.

21. Fletcher C.M Elmes P.C, Fairbairn A.S, et al. The significance of respiratory symptoms and the diagnosis of chronic bronchitis in a working population. Br Med J 1959;2:257-66.

22. Mahler DA, Wells CK. Evaluation of clinical methods for rating dyspnea. Chest 1988;93:580-6.

23. Mahler DA, Weinberg DH, Wells CK, et al. The measurement of dyspnea. Contents, interobserver agreement, and physiologic correlates of two new clinical indexes. Chest 1984;85:751-8.

24. Hayes MHS, Patterson D. Experimental development of the graphic rating method. Psychol Bull 1921;18:98-9.

25. Jones PW, Quirk FH, Baveystock CM, et al. A selfcomplete measure of health status for chronic airflow limitation. The St. George's Respiratory Questionnaire. Am Rev Respir Dis 1992;145:1321-7.

26. Yorke J, Jones PW, Swigris JJ. Development and validity testing of an IPF-specific version of the St George's Respiratory Questionnaire. Thorax 2010;65:921-6.

27. Ware JE Jr, Sherbourne CD. The MOS 36-item shortform health survey (SF-36). I. Conceptual framework and item selection. Med Care 1992;30:473-83. 
28. Downs SH, Black N. The feasibility of creating a checklist for the assessment of the methodological quality both of randomised and non-randomised studies of health care interventions. J Epidemiol Community Health 1998;52:377-84.

29. Munn J, Sullivan SJ, Schneiders AG. Evidence of sensorimotor deficits in functional ankle instability: a systematic review with meta-analysis. J Sci Med Sport 2010;13:2-12.

30. Melsen WG, Bootsma MC, Rovers MM, et al. The effects of clinical and statistical heterogeneity on the predictive values of results from meta-analyses. Clin Microbiol Infect 2014;20:123-9.

31. Dowman LM, McDonald CF, Hill CJ, et al. The evidence of benefits of exercise training in interstitial lung disease: a randomised controlled trial. Thorax 2017;72:610-9.

32. da Fontoura FF, Berton DC, Watte G, Florian J, et al. Pulmonary rehabilitation in patients with advanced idiopathic pulmonary fibrosis referred for lung transplantation. J Cardiopulm Rehabil Prev 2018;38:131-4.

33. Kozu R, Jenkins S, Senjyu H. Effect of disability level on response to pulmonary rehabilitation in patients with idiopathic pulmonary fibrosis. Respirology 2011;16:1196-202.

34. Ozalevli S, Karaali HK, Ilgin D, et al. Effect of homebased pulmonary rehabilitation in patients with idiopathic pulmonary fibrosis. Multidiscip Respir Med 2010;5:31-7.

35. Nishiyama O, Kondoh Y, Kimura T,et al. Effects of pulmonary rehabilitation in patients with idiopathic pulmonary fibrosis. Respirology 2008;13:394-9.

36. Jackson RM, Gomez-Marin OW, Ramos CF, et al. Exercise limitation in IPF patients: a randomized trial of pulmonary rehabilitation. Lung 2014;192:367-76.

37. Vainshelboim B, Oliveira J, Yehoshua L, et al. Exercise training-based pulmonary rehabilitation program is clinically beneficial for idiopathic pulmonary fibrosis. Respiration 2014;88:378-88.

38. Swigris JJ, Fairclough DL, Morrison M, et al. Benefits of pulmonary rehabilitation in idiopathic pulmonary fibrosis. Respir Care 2011;56:783-9.

39. Rammaert B, Leroy S, Cavestri B, et al. Home-based pulmonary rehabilitation in idiopathic pulmonary fibrosis. Rev Mal Respir 2011;28:e52-7.

40. Arizono S, Taniguchi H, Sakamoto K, et al. Pulmonary rehabilitation in patients with idiopathic pulmonary fibrosis: comparison with chronic obstructive pulmonary disease. Sarco Vasc Dif lung dis 2017;34:283-289.

41. Holland AE, Hill CJ, Glaspole I, et al. Predictors of benefit following pulmonary rehabilitation for interstitial lung disease. Respir Med 2012;106:429-35.

42. Rifaat N, Anwar E, Ali YM, et al. Value of pulmonary rehabilitation in patients with idiopathic pulmonary fibrosis. Egypt J Chest Dis Tuberc 2014;63:1013-7.

43. Arizono S, Taniguchi H, Sakamoto K, et al. Endurance time is the most responsive exercise measurement in idiopathic pulmonary fibrosis. Respir Care 2014;59:1108-15.

44. du Bois RM, Weycker D, Albera C, et al. Six-minute-walk test in idiopathic pulmonary fibrosis: test validation and minimal clinically important difference. Am J Respir Crit Care Med 2011;183:1231-7.

45. Nykvist SM, Ferrara G, Faager G. Inspiratory muscle training in addition to physical exercise for idiopathic pulmonary fibrosis. Eur Respir J 2016;48:OA1518.

46. O'Donnell DE, D'Arsigny C, Webb KA. Effects of hyperoxia on ventilatory limitation during exercise in advanced chronic obstructive pulmonary disease. Am J Respir Crit Care Med 2001;163:892-8.

47. Ryerson CJ, Cayou C, Topp F, et al. Pulmonary rehabilitation improves long-term outcomes in interstitial lung disease: a prospective cohort study. Respir Med 2014;108:203-10.

48. Verma G, Marras T, Chowdhury N, et al. Health-related quality of life and 6 minute walk distance in patients with idiopathic pulmonary fibrosis. Can Respir J 2011;18:283-7.

49. Jones PW. St. George's Respiratory Questionnaire: MCID. COPD 2005;2:75-9.
Cite this article as: Hanada $M$, Kasawara KT, Mathur S, Rozenberg D, Kozu R, Hassan SA, Reid WD. Aerobic and breathing exercises improve dyspnea, exercise capacity and quality of life in idiopathic pulmonary fibrosis patients: systematic review and meta-analysis. J Thorac Dis 2020;12(3):1041-1055. doi: 10.21037/jtd.2019.12.27 


\section{Supplement A Details of Medline search strategy}

1. Idiopathic Pulmonary Fibrosis/

2. Idiopathic Interstitial Pneumonias/

3. Lung Diseases, Interstitial/

4. exp Pulmonary Fibrosis/

5. (idiopathic pulmonary adj (fibros* or pneumon*)).tw,kf.

6. ipf.tw,kf.

7. (idiopathic lung adj (fibros* or pneumon $\left.{ }^{*}\right)$ ).tw,kf.

8. (idiopathic interstitial adj (fibros* or pneumon*)).tw,kf.

9. idiopathic fibros*.tw,kf.

10. fibrosing alveolit*.tw,kf.

11. interstitial lung disease?.tw,kf.

12. ((chronic or usual or fibrosing) adj interstitial pneumon*).tw,kf.

13. UIP.tw,kf.

14. ((interstitial fibros* or alveolar fibros*) adj5 (lung? or pulmonary)).tw,kf.

15. (diffuse adj5 (lung? or pulmonary) adj5 fibros*).tw,kf.

16. ((parenchymal or fibrotic or restrictive) adj lung disease $\left.^{*}\right)$.tw,kf.

17. ((non-specific or nonspecific) adj interstitial pneumon*). tw,kf.

18. ((non-specific or nonspecific) adj interstitial fibros*). tw, kf.

19. NSIP.tw,kf.

20. ((lung? or pulmonary or interstitial) adj fibros*).tw,kf.

21. or $/ 1-20$

22. exp Exercise/

23. exp Exercise Therapy/

24. exp Exercise Movement Techniques/

25. Physical Fitness/

26. exp "Physical Education and Training"/

27. (exercise* or exercising).tw,kf.

28. (gi gong or gigong).tw,kf.

29. ((tai adj ji) or ((tai or thai) adj chi) or taiji or taijiquan or taichi).tw,kf.

30. walking.tw,kf.

31. yoga.tw,kf.

32. (physical adj (fitness or condition* or education or training or mobility or activit* or exertion or effort)). tw,kf.

33. gymnastic*1.tw,kf.

34. calisthenics.tw,kf.

35 . aerobic* $1 . \mathrm{tw}, \mathrm{kf}$.

36. danc*.tw,kf.

37. (jumping or hopping).tw,kf.

38. (running or jogging).tw,kf.

39. ambulat*.tw,kf.

40. muscle strengthening.tw,kf.

41. ((strength or resistance) adj training).tw,kf.

42. ((weight*1 adj2 lifting) or weightlifting or power lifting or weight training).tw,kf.

43. pilates.tw,kf.

44. stretching.tw,kf.
45. plyometric*.tw,kf.

46. (cardio* adj conditioning).tw,kf.

47. ((physical or motion or movement or recreation or activity or pulmonar*) adj (rehab* or therap*)).tw,kf.

48. isometric training.tw,kf.

49. climbing.tw,kf.

50. cycling.tw,kf.

51. (swim or swimming).tw,kf.

52. (training adj (course* or program*)).tw,kf.

53. kinesi? therap*.tw,kf.

54. exp Sports/

55. Rehabilitation/

56. Physical Therapy Modalities/

57. "Physical Education and Training"/

58. ((interval or endurance) adj train*).tw,kf.

59. dance therapy/

60. or $/ 22-59$

61. Breathing Exercises/

62. exp Respiratory Muscles/ph

63. ((inspirator* or expirator* ${ }^{*}$ or respirator ${ }^{*}$ or ventilator*) adj3 train*).tw,kf.

64. (isocapn* adj3 (hyperpn* or hyperventila*)).tw,kw.

65. (PFlex or powerlung).tw,kf.

66. PImax.tw,kf.

67. PEmax.tw,kf.

68. (Max* inspirator* adj2 Pressure*).tw,kf.

69. $\left(\right.$ Max $^{*}$ expirator* adj2 Pressure* ${ }^{*}$.tw,kf.

70. (Max* respirator* adj2 Pressure*).tw,kf.

71. (breath* adj3 exercis*).tw,kf.

72. ((inspirator ${ }^{*}$ or expirator ${ }^{*}$ or respirator ${ }^{*}$ or threshold*) adj3 load*).tw,kf.

73. ((inspirator* or expirator* or respirator ${ }^{*}$ or threshold*) adj3 device?).tw,kf.

74. Maximal Respiratory Pressures/

75. exp Inspiratory Capacity/

76. or/61-75

77. exp Dyspnea/

78. dyspn? ea?.tw,kf.

79. breathlessness*.tw,kf.

80. breathless-ness* ${ }^{*}$.tw,kf.

81. (breath adj2 short*).tw,kf.

82. or/77-81

83. exp physical endurance/ or exercise tolerance/

84. (exercis* adj2 (toleran* or capacit*)).tw,kf.

85. (aerobic* adj2 (toleran* or capacit*)).tw,kf.

86. (function* adj2 capacit*).tw,kf.

87. or/83-86

88. 21 and (60 or 76$)$ and ( 82 or 87$)$

89. limit 88 to english

90. limit 88 to japanese

91. 89 or 90

92. 91 not (exp animals/ not exp humans/)

93. 92 not ((exp children/ or exp infant/ or exp adolescent/) not (exp adults/ or exp aged/)) 